\title{
The Management of E-Commerce in the Kingdom of Saudi Arabia: An Exploratory Research
}

\author{
Dr. Mohammad Ziaul Hoq \\ Jubail Industrial College, Royal Commission of Jubail, Kingdom of Saudi Arabia. \\ Email: mohammad_z@jic.edu.sa
}

\begin{abstract}
E-commerce is the technology of recognizing commercial dealings via electronic channel. The Internet has offered this channel to the point that trade is being more and more prepared through it. This article observes topics such as the circumstances, acknowledgements etc. of e-commerce in Saudi Arabia. Furthermore, a comprehensive literature review was conducted about numerous characteristics of e-commerce. The results of the study might shed light to the contemporary e-commerce development topics in Saudi Arabia, which could be constructive for the industry as well as for the academia.
\end{abstract}

Keywords: E-commerce, Saudi Arabia, Vision 2030, Online market.

DOI: $10.7176 / \mathrm{EJBM} / 12-6-13$

Publication date: February $29^{\text {th }} 2020$

\section{Introduction}

The meaning of e-commerce is the electronic route by which persons or establishments make a deal, like purchase, trade, interchange of goods / services etc. (Turban, McLean and Weatherbe 2004). In summary, e-commerce successfully removes the need of massive funds or outlays on physical structure (i.e. physical shopping mall, offices etc.). For emerging nations, it has the prospective to show answers to various complications such as facility of distant healthcare and learning. Nevertheless, these nations are incompetent to gain advantages, as there is an enormous dissimilarities between the acceptance rates, execution and practice of e-commerce in advanced and emerging countries (Alyoubi, 2015).

On the other hand, the notion of e-commerce developed in 1990s with the potential of prolonged commercial procedures and benefits for various kinds of firms. Though there was a bit of initial investigation on Internet, not ample investigation was conducted in the area of e- commerce till voluminous firms became insolvent in the dotcom-bubble-era (i.e. 1998 to 2000). From the destruction generated by various unsuccessful "dot.com" firms, the executives of these firms initiated to comprehend that rather than having an apparently credible notion (Turban et al., 2004). Moreover, various initial e-commerce disappointments were the outcomes of not evolving a rigorous commercial prototype (Vickers, 2000).

Although, Webvan, e-grocery firm with 1 billion USD investment eventually was unsuccessful, the computer firm Dell went on to make a fruitful e-commerce business prototype (Laseter et al., 2003; Laudon and Traver, 2006). After the dotcom-bubble burst, many investigations were completed, which intended to control the features which might guide consumers to ponder e-commerce with or as an substitute to go to "brick and mortar" malls (Ezzi, 2016).

In addition, from early 2000's, a significant number of consumer behavior study started that wanted to detect the elements which inspire the customers to ponder online business. However, realizing the motivation for customers to ponder e-commerce while essential is not adequate for firms to gain the advantages of e-commerce (Ezzi, 2016).

Furthermore, in the e-commerce atmosphere, business to consumer commerce had advanced swiftly (Alden et al., 2006; Holt et al., 2004). E-commerce creates prospects for firms to attract customers universally. As a result, commerce and humanity studies progressively pay attention to cross-national e- marketing (Griffith et al., 2006). Moreover, e-commerce dealings are rising in the Middle East (19.5 million internet users) as well as in Arab nations. In K.S. A. e-commerce dealings augmented by 100 per cent, from \$278 million in 2002 to \$556 million in 2005 (Al Riyadh, 2006). Nevertheless, this perspective of extraordinary progress is somehow underinvestigated. 


\section{Methodology}

The research methodology of this research is of an exploratory type. It is considered suitable for the objective of this study. This study mainly focuses on the review of available literatures. The objective is to propose an overview of substantial literature available on e-commerce as a preliminary study that could guide to additional investigation and support to this area of research. The study wishes to offer realization of topics, unsettled queries, problems and focus on some aspects that could assist the success of e-commerce in Saudi Arabia.

\section{Saudi Vision 2030 and E-Commerce}

Vision 2030 of Kingdom of Saudi Arabia states:

"We aim to provide job opportunities for an additional million Saudis by 2020 in a growing retail sector that attracts modern, local, regional, and international brands across all regions of the country. We also aim to increase the contribution of modern trade and e-commerce to 80 percent of the retail sector by 2020 ."

Vision 2030 of Kingdom of Saudi Arabia (K.S.A.) is the vision for the future of Kingdom. It is an aspiring outline of robust goals and prospects. The regime has decided to follow government and private co-operations, continue to ease the movement of private ventures and increase the attractiveness of the economy of the kingdom. Judicial establishments have been involved to study the existing rules to eventually improve the trade atmosphere. The 'thriving economy' feature of the strategy is fundamentally dependent on nation's capacity to expand its economy and shrink its dependence on oil. The alteration of the economy will have varied implications on the information and communication technology segment, comprising the review of the controlling charter, augmented call for innovative prospects for IT concentrated companies (i.e. e-commence, online shopping etc.).

Moreover, a fundamental portion of the Saudi Vision 2030 is to increase efficiency and be one of the leading economy in the globe. Portion of the growth of Saudi Arabia is the assurance to raise the retail segment and confirm that contemporary business and e-commerce add to $80 \%$ of the retail segment by 2020 . E-commerce permits consumers to shop anywhere and anytime they want. Given the appetite of Internet dissemination and e-commerce in Saudi Arabia, commercial activities in K.S.A. will be more fortified through the support of Internet. For example, homecentre.com website is the first of many phases that have intended to deliver the devoted consumers with an online-channel familiarity as well as provide them a more appropriate shopping experience (Khwaja, 2017).

On the other hand, the Vision has recognized that old-style merchandizing controls around $50 \%$ of the market in Saudi compared to $20 \%$ in Gulf Cooperation Council (GCC), with the retail shop distressing from inadequate dissemination of contemporary business and e-commerce. The administration targets to rise the input of up-to-date trade and e-commerce to $80 \%$ in the retail segment by 2030. This is intended to be attained by appealing both local and global retail stakeholders, aggregating funding of minor retail firms to inspire their progress and expansion and by reducing restraints on proprietorship and external investment (Khwaja, 2017).

\section{Online Market In Saudi Arabia}

The Saudi e-retail trade was around $\$ 1.6$ billion in 2018. Saudi customers have a high propensity to procure electronic goods online, while to procure foodstuff and drinks is virtually entirely offline. Foodstuff and drinks are the main expenses ( $\$ 65.8$ billion), however they count for 3 percent of e-commerce revenues. On the other hand, electronics are the minimum expenses but count for a fifth of online sales. These statistics place the Saudis like a traditionalist, risk-averse online customers who merely purchase pre-identified articles online (Garrós, 2019).

The classic Saudi online purchaser is typically a native lady, residing in Riyadh or Jeddah and compensate for the procurements with cash on delivery. About 74 percent of e-commerce customers are 18 to 34 years of age and generally buy electronics and domestic goods. The small credit card penetration leads to 66 percent of businesses are completed utilizing cash on supply. There is limitation in credit card acceptance from the Saudi people, making an obstacle for online trade. Furthermore, it is tough for e-commerce companies to administer their capital as cash on supply is the favored compensation system in the kingdom (Garrós, 2019). 


\section{NUMBER OF ONLINE SHOPPERS IN SAUDI ARABIA} (in millions)

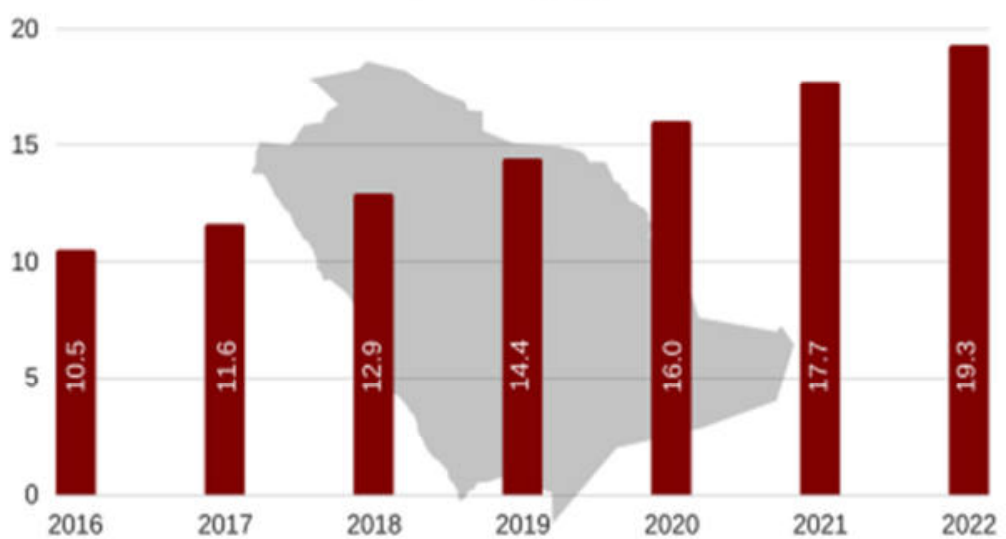

Figure1: Number of online shoppers in K.S.A. (in millions)

In spite of having extraordinary online savviness, Saudi Arabian e-commerce sector is developing slowly. With an intake per capita of $\$ 8,329$ plus the second leading mobile broadband saturation in the world, Saudi Arabia has merely 1.4 percent of e- retail concentration. Smartphones have a tendency to be utilized for social media, where the mediocre Saudi passes 7 hours per day (Garrós, 2019).

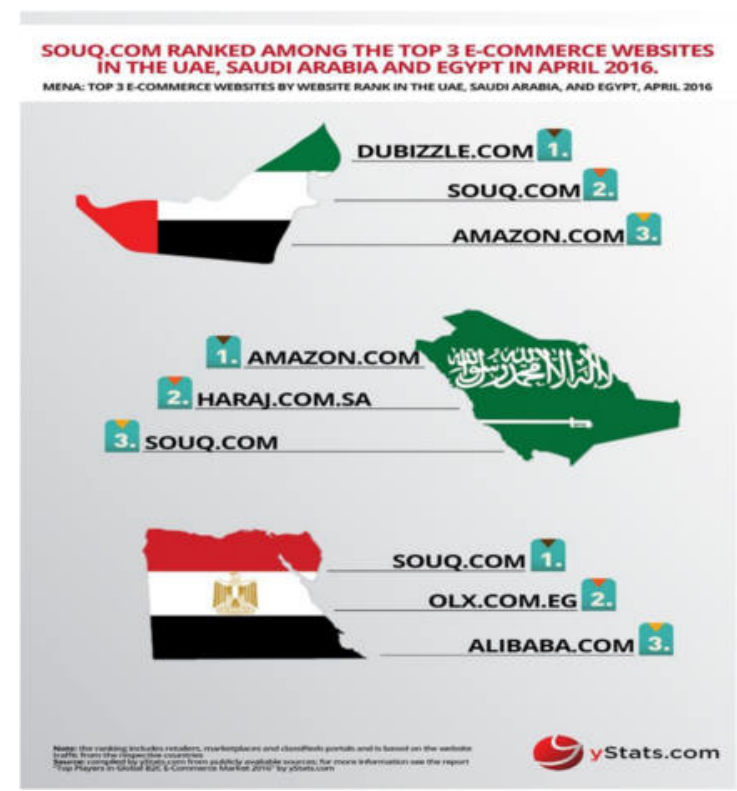

Source: ystats.com

Figure2: Souq.com ranked the top 3 e-commerce websites in 2016. 
Moreover, Saudi Arabia possesses the accurate combination of elements to safeguard online retail market accomplishment and upcoming development, like the scope of the market that could guide proper quantities as well as economies of scale and effectiveness. With intake of about $\$ 270$ billion, Saudi Arabia is the Middle East's principal market. In addition, an e-commerce law is being prepared with the aim of encouraging reliable atmosphere for e-commerce (Garrós, 2019).

\section{Internet Consumption in Saudi Arabia.}

Internet penetration is enormously high in Saudi Arabia, particularly in comparison to different nations in the Middle East. Roughly 20,813,695 citizens utilize the Internet - which is roughly a 64.7 percent penetration rate. This level has quickly developed from 2.2 percent in 2000. The rapid growth of Internet in the previous 16 years has been vastly dominant for the nation - 7.96 million citizens used Facebook in 2016 and it is identified for its extensive use of YouTube, with the residents accountable for approximately 90 million observations per day (Istizada, 2019).

As per the Alexa.com, highly viewed website is as per following:

1. Google.com

2. Youtube.com

3. Google.com.sa

4. Sabq.org

5. Live.com

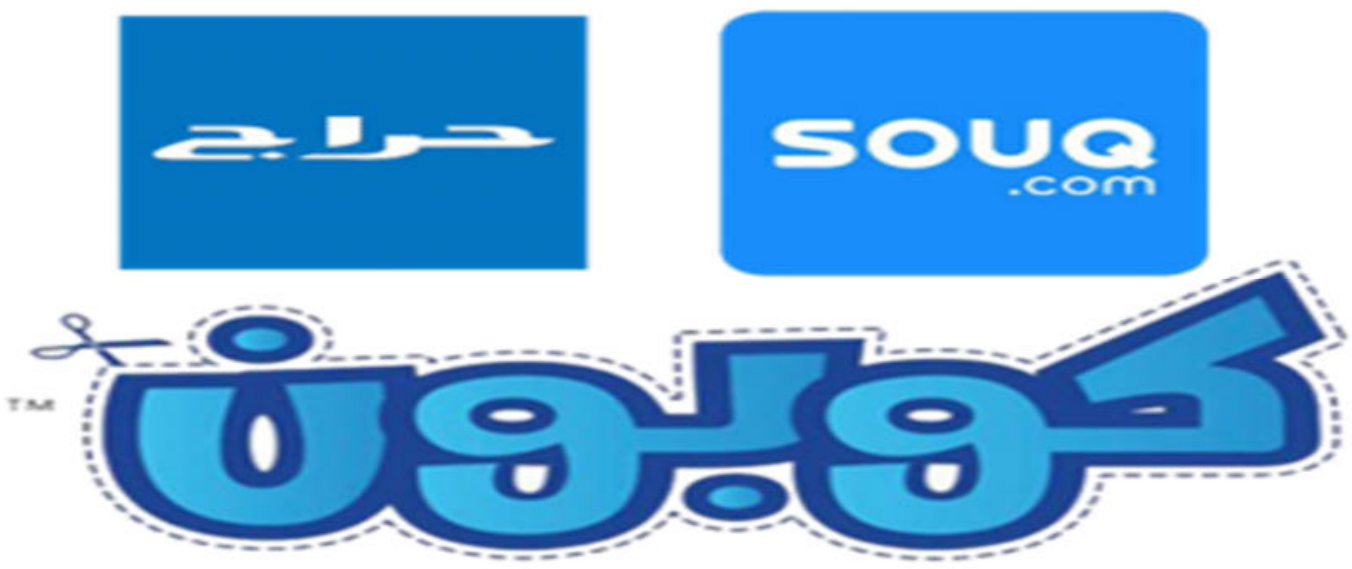

Source: http://istizada.com/ecommerce-in-saudi-arabia-the-complete-guide/

Figure3: Top e-commerce site in K.S.A.

Moreover, the highly viewed e-commerce websites in Saudi Arabia are Souq.com, Haraj.com.sa and Amazon. Other high ranking websites include Apple, Opensooq.com, Aliexpress, Jarir.com, Extrastores.com, Alibaba and eBay.

Similarly, the bulk of this list is usual for any other nation, with Google plus several social media sites controlling the list of maximum viewed websites. Conversely, it is also a thrilling list for those desiring to finance in online business in Saudi Arabia. Haraj.com.sa is an online auction site where as souq.com is a common website for the Middle-East that is more as amazon.com. The existence of these two websites on the list advocates high assurance in e-commerce dealings. (Istizada, 2019).

In fact, these sites are largely e-commerce websites concentrated to a wide Middle-Eastern customers. Still, Saudi Arabia creates a huge quantity of the movement to these websites - closely 23 percent of the traffic to souq.com, 22 percent to jarir.com, and 21 percent to opensooq.com. 


\section{E-Commerce in K.S.A : Case Study of Home Centre}

Online business as a channel, possesses robust progress probability in Saudi Arabia, Mederic Payne, the CEO of Home Centre, told in a meeting. According to him, with the rise of online, societal and mobile equipment, customers are altering the method of their shopping. As a result, homecentre.com have launched online platform for its customers. Although offline set-up will stay to be significant for Home Centre, online platform may carry superior comfort to the consumers. It may support the brand to increase its market share without the restrictions of physical borders. Moreover, Internet diffusion in Saudi Arabia is presently at 75 percent, and is anticipated to hold above 90 percent by 2020 . Smartphone saturation is 66.3 percent and is estimated to reach to 69 percent by 2020 (Arab Finance, 2017).

Home Centre has financed sensibly in establishing shops in the precise sites in previous two decades. Their online and offline establishments are equally vital and applicable to the consumers. Whereas spending in virtual environment offers comfort and handiness, the notion of going to a shop and touching cabinets, chairs, tables etc. may not decrease. Home Centre considers that online and offline platforms may support each other. However, it will adopt more aggressive online strategy in future. Its online gateway is the lone passage which let them show their complete assortment of goods. The extensive offering of goods is supported by special paybacks that enlarge benefits to e-commerce experiences, for example on time distributions, precise supply and several payment choices (Arab Finance, 2017).

\section{Future of E-Commerce in Saudi Arabia}

Spending in retail sector of K.S.A. will remain robust. Spending in retail sector anticipated to develop at 4.5 percent CAGR, aggregating from $\$ 124$ billion in 2018 to around $\$ 170$ billion in 2025 . Foodstuff and drinks will be the leading sector getting $\$ 94$ billion in 2025 . Rising rivalry, decent entrance to technological and managerial knowhow as well as enlightening entrance to finance are the vital features driving growth of e-commerce in K.S.A.

Table 1: E-commerce Users by Age Group in millions

\begin{tabular}{|l|l|l|l|l|l|l|l|}
\hline & \multicolumn{1}{|c|}{$\mathbf{2 0 1 4}$} & \multicolumn{1}{|c|}{$\mathbf{2 0 1 5}$} & \multicolumn{1}{|c|}{$\mathbf{2 0 1 6}$} & \multicolumn{1}{|c|}{$\mathbf{2 0 1 7}$} & \multicolumn{1}{|c|}{$\mathbf{2 0 1 8}$} & \multicolumn{1}{|c|}{$\mathbf{2 0 1 9}$} & \multicolumn{2}{|c|}{$\mathbf{2 0 2 0}$} \\
\hline $16-24$ & 2.077 & 2.303 & 2.529 & 2.753 & 2.978 & 3.188 & 3.377 \\
\hline $25-34$ & 4.26 & 4.846 & 5.463 & 6.107 & 6.789 & 7.473 & 8.142 \\
\hline $35-44$ & 1.646 & 1.911 & 2.202 & 2.51 & 2.842 & 3.183 & 3.525 \\
\hline $45-54$ & 0.411 & 0.501 & 0.608 & 0.731 & 0.876 & 1.04 & 1.223 \\
\hline $55+$ & 0.14 & 0.202 & 0.287 & 0.39 & 0.518 & 0.67 & 0.847 \\
\hline
\end{tabular}

Source: https://www.go-gulf.com

Furthermore, Saudi "mixed" virtual retail saturation is predicted to touch the UAE's contemporary virtual saturation of $3.2 \%$ between 2020 and 2021 . Electronic goods will stay the utmost advanced followed by home appliances with 33\% and 12\% online saturation respectively in 2025 (Garrós, 2019).

Table 2: E-commerce revenue by category

\begin{tabular}{|l|l|l|l|l|l|l|}
\hline \multicolumn{1}{|c|}{ Category } & \multicolumn{1}{c|}{2015} & \multicolumn{1}{c|}{2016} & \multicolumn{1}{c|}{2017} & \multicolumn{1}{c|}{2018} & \multicolumn{1}{c|}{2019} & 2020 \\
\hline Clothes \& Shoes & 1,591 & $1,893.5$ & 2188.9 & 2510.7 & 2866.5 & 3209.5 \\
\hline Consumer electronics & 1805.5 & $2,037.6$ & 2262.7 & 2487.6 & 2747.2 & 2998.9 \\
\hline $\begin{array}{l}\text { Food, cosmetics and } \\
\text { Pharmaceuticals }\end{array}$ & 409.8 & 472.2 & 542.1 & 615.3 & 693.1 & 776.8 \\
\hline $\begin{array}{l}\text { Furniture \& Home } \\
\text { Appliances }\end{array}$ & 669.9 & 808.1 & 952 & 1112.9 & 1284.4 & 1477.5 \\
\hline
\end{tabular}

Source: https://www.go-gulf.com 
Besides, the configuration of the e-commerce is anticipated to advance from present customer electronics focused market to a further stable market with style, fixtures, personal care, foodstuff and drinks contributing around $11 \%$ $16 \%$ each. Personal care, style and fixtures virtual retail markets are estimated to touch $\$ 1.5$ billion by 2021 (Garrós, 2019).

\section{Advantages of E-Commerce}

The increasing reputation of online business is logical as finding and purchasing a product in physical shops is very time consuming and stressful. Purchasing in virtual environment for goods, with a mouse click away, has supreme benefits (Henari et al. 2008).

Moreover, online business facilitates consumers $24 \times 7$ entree around the clock, to purchase from practically any place. Likewise, consumers are exposed to other options such as more comfortable purchasing as well as availability of cheaper goods. Consumers may get significant and comprehensive information in very short time. Getting the related data guides the consumers to take up-to-date judgments and it aids to improve their gratification (Jelassi and Leenen, 2003). Alternative advantage is that one consumer may cooperate with another consumer in online environment. They may interchange ideas and related know-hows. A supplementary value is that ecommerce simplifies rivalry, which ends in generous sales promotions (Wilson and Abel, 2002).

\section{Disadvantages of $\mathbf{E}$-Commerce}

Although in one hand e-commerce possess advantages, on the other hand, it also holds its disadvantages, both technical and non-technical. In case of technical disadvantages, one focal concern is shortage of systems' safety, trustworthiness and ethics as well as communication procedures. In addition, the equipment to develop software is progressing till now with rapid changes (Schneider, 2004). There are complications in incorporating the Internet and e-commerce software with prevailing applications and databanks. One more constraint is potential difficulties of interoperability, which means that a few software may not be suitable with hardware, or is irreconcilable with operating systems. Additionally, there is the necessity for distinct infrastructures (i.e. website server, network server etc.), which may lead to extra costs (Turban et al. 2004).

As opposed to non-technical limitations, technical limitations may be resolved by devoting sufficient cash (Spiliopoulos, 2007). Conversely, non-technical limitations are issues that are challenging to alter as they comprise behavioral features - such as attitude, shortage of confidence, readiness to change, etc. which involve substantial energy and time to amend. (Henari et al. 2008).

A few non-technical complications are a following:

- privacy issues;

- shortage of guidelines and procedures on Internet;

- anxiety of unsatisfied customers;

- deficiency of confidence; and

- communication hurdle

\section{Challenges of $E$-Commerce}

From its starting, e-commerce encountered numerous complications and hurdles that have virtually ruined its progress. Nevertheless, those hurdles generated several way out that facilitated e-commerce to reach to current stage (Expandcart, 2019).

A few of the hurdles e-commerce is facing in Saudi Arabia are given below:

\subsection{Price of possessing an e-commerce store}

High budget is one of the biggest difficulties faced by an e-commerce firm in K.S.A. It has disrupted growth of ecommerce in the Kingdom. However, development of various Arab firms that offer way out to e-commerce problems as well as know-how at cheaper price facilitated to lighten that hurdle.

\subsection{Distribution of products}

Distribution of products in Saudi Arabia are tarnished by some drawbacks, predominantly upper costs and low standard service, which played a big role in deterring the development of e-commerce. 


\subsection{Full Arabic language support in online stores}

Another challenge of e-commerce in Kingdom is the absence of support of the Arabic language. It has been a key hurdle to companies desiring to assist all online consumers in the Kingdom.

\subsection{Payment related challenges}

Fear related to online payment is another obstacle that is obstructing the swift progression of e-commerce in Saudi Arabia. There is prevalent anxiety among Saudis concerning fraud related to their bank account. As a result, cash on delivery is the common system in the Kingdom. The low popularity of credit cards and limits on their online use are similarly aiding to hamper the success of online business.

\subsection{Acquire goods for e-commerce}

Another challenge of e-commerce in the Kingdom is to deliver and attain the goods they sell. Initially, e-commerce obliges a precise item that may be traded over a virtual shop. So it is difficult to start an online store in Kingdom as businessmen do not know how to deliver a product for the shop (Expandcart, 2019).

\subsection{Legal challenges}

Legal problems are another complications to the advancement of e-commerce in the Kingdom. Numerous virtual store proprietors experience various legal difficulties connected to the legal circumstances from a commercial register as well as other department.

\subsection{Online Marketing}

Several e-commerce dealers trust that possessing an online business is everything and it will instantly commence selling and making revenues. Nevertheless, it's rather dissimilar from that conviction. In reality it requires digital marketing efforts to reach the customers and shoppers.

In addition, e-marketing is one of the utmost significant difficulties facing e-commerce in the Kingdom. As a result, e-commerce owners should be careful to online marketing. They should create marketing plans and tactics that assist the success of online stores (Expandcart, 2019).

\section{Features Driving E-Commerce}

\subsection{Trust}

Trust is an important element in e-commerce. It provides consumers confidence to purchase goods although etrader could be anonymous. It inspires usage of technology, makes the e-payment procedure comfortable, elevates consumer gratification, leads to loyalty, builds long-term associations with consumers and helps to obtain a competitive advantage. However, according to Klang (2001) and Ratnasingham and Kumar (2000), Kabango and Asa (2018) only the mechanical views may not assure trust in e-commerce.

\subsection{Safety, Fraud and Hacking}

It is extensively recognized by public and private establishments that concerns of information safety are a key hurdle to the development of e-commerce. The observation of threat concerning Internet safety has similarly been documented as an anxiety for the customers (Miyazaki and Fernandez, 2001). Additionally, Miyazaki and Fernandez (2001) have acknowledged that one of the key concerns for e-commerce users is the fake attitude of online vendors. Likewise, Rose et al. (1999) classifies hackers as an apparent security risk to online trade. This occurs as the online approachability of the data of various companies provides a hacker the opportunity to take data from the databanks. These dangers have been recognized in numerous studies (Al-Ghaith et al., 2010). Moreover, Dixit and Datta (2010) examined the approval of online banking among consumers. The results illustrated that several aspects like safety, secrecy and confidence escalate the approval of online banking facilities among the consumers (Kabango and Asa 2018).

\subsection{Awareness and Usefulness}

Ample study has sketched the importance of the influence of perceived effectiveness on behavior to the use of ecommerce. The actual motive of consumers to practice e-commerce is the ease and convenience of online shopping (Alghamdi, 2011). On the other hand, according to Sathye's (1999) the absence of knowledge of e-commerce is a fundamental aspect in averting consumers from accepting it. Moreover, Suki and Ramayah (2010) investigated customer approval of the e-government facilities in Malaysia. Their findings show that the essential elements of customer approval of the e-government facilities are perceived effectiveness, comfort, behavior etc. (Kabango and Asa 2018). 


\subsection{Role of Government}

The government may play a central role for the growth of e-commerce. For example, delivering protected online payment choices, safeguarding a concrete ICT framework, delivering enlightening courses and developing awareness utilizing various means (i.e. Internet, radio, television etc.). The findings of the research demonstrate that government support is a crucial factor of e-commerce (AlGhamdi et al., 2011). In Saudi Arabia, Eid (2011) postulate in his research that the Government's support was documented as a significant component in the improvement of e-commerce. Moreover, the trustworthy postal facility is also vital for e-commerce (Kabango and Asa 2018).

\section{Conclusion}

Although the traditional mode of buying by Saudi customers is the dominated way, however, there are enthusiastic methods of customers to e-commerce. It became reality because of consumers' appreciation of e-commerce as well as their association in using computers and the high consumption of Internet to discover various goods. On the contrary, Saudi consumers are still unsure concerning safety and privacy issues related to e-commerce. Customers are concerned to have their personal data in the improper hands or their credit card records be occupied by hackers. It has been found that the vital challenge in recognizing e-commerce is lack of strong laws for ecommerce, online crime, data security \& privacy as well as complications in combining e-commerce with present arrangement.

\section{References}

Alden, D. L., Jan B. E., Steenkamp, M. \& Rajeev, B. (2006). Consumer attitudes toward marketing globalization: antecedent, consequent and structural factors. International of Research in Marketing, 23(3), 227 -39.

Alyoubi, A.A. (2015). International Conference on Communication, Management and Information Technology (ICCMIT 2015). Procedia Computer Science, 479 - 483.

Al-Ghaith, W. A., Sanzogni, L., \& Sandhu, K. (2010). Factors influencing the adoption and usage of online services in Saudi Arabia. The Electronic Journal of Information Systems in Developing Countries, 15(3), 40-49

Al-Ghamdi, R., Steve D., and Osama A.(2011) .Issues influencing Saudi customers' decisions to purchase from online retailers in the KSA: a qualitative analysis. ” European Journal of Scientific Research 55 (4), 580-593.

Al Riyadh (2006). Challenge of e-com in Saudi Arabia, 43(27), available at: www.alriyadh.com/2006/08/27/article182047.html, Retrieved on 05 Nov., 2019.

Arab Finance (2017). E-commerce in Saudi Arabia has strong growth potential. Cairo, Egypt.

Cyr, D. (2008). Modeling web site design across cultures: relationships to trust, satisfaction, and e-loyalty. Journal of Management Information Systems, 24(4), 47-72.

Dixit, N., \& Datta, S. K. (2010). Acceptance of E-banking among Adult Customers: An Empirical Investigation in India. Journal of Internet Banking \& Commerce, 15(2), 50-58.

Eid, M. I. (2011). Determinants of e-commerce customer satisfaction, trust, and loyalty in Saudi Arabia. Journal of Electronic Commerce Research, 12(1), 78-93.

Eshopwold (2020). Saudi Arabia e-commerce Insights. Retrieved January, 2020 from https://learning.eshopworld.com/ecommerce-blog/saudi-arabia-ecommerce-insights-2018/

Ezzi, S. W. (2016). Exploring the Characteristics of the E-commerce Marketplace in Saudi Arabia, International Journal of Economic Perspectives; 10 (4), 5-20.

Expandcart (2019). Top Challenges Facing E-Commerce in Saudi Arabia. Retrieved November, 2019 from https:/www.expandcart.com/en/28835-top-challenges-facing-e-commerce-in-saudi-arabia.

Garrós, M. (2019). A diamond in the desert: Saudi Arabia's e-commerce market is poised to boom. The Delta Perspective.

Go-gulf (2020). E-commerce in Saudi Arabia - Statistics and Trends. Retrieved February, 2020 from https://www.go-gulf.com/ecommerce-saudi-arabia/. 
Griffith, D. A., Matthew B. M., and Michael G. H. (2006). An Investigation of National Cultures' Influence on Relationship and Knowledge Resources in Inter-organizational Relationships between Japan and the United States. Journal of International Marketing, 14(3), 1-32.

Henari, Tara Fryad; Mahboob, Roohi.Education, Business and Society: Contemporary Middle Eastern Issues; Bingley,1(3), (2008): 213-220. DOI:10.1108/17537980810909832

Holt, Douglas B., John A., Quelch, and Earl L. Taylor (2004). How Global Brands Compete.

Harvard Business Review, 82(9), 68-75.

Istizada (2019). http://istizada.com/ecommerce-in-saudi-arabia-the-complete-guide/, retrieved on Retrieved on 15 Nov., 2019.

Jelassi, T. and Leenen, S. (2003). An e-commerce sales model for manufacturing organizations: a conceptual framework and a European example. European Management Journal, 21(1), 38-47.

Khwaja (2017). Technology, Media \& Telecommunications, Dubai International Financial Centre. Dubai, U.A.E.

Kabango, C.M. and Asa, A.R. (2018). Factors Influencing E-commerce Development: Implications for the Developing Countries. International Journal of Innovation and Economic Development, 1(1), 59-66.

Klang, M. (2001). Who do you trust? Beyond encryption, secure e-business. Decision Support Systems, 31(3), 293-301,

Laseter, T., Berg, B. and Turner, M. (2003). What fresh direct learned from dell. Strategy + Business, Spring (30), Strategy\& Business. NY: Formerly Booz \& Company: 26-34.

Laudon, K.C. and Traver, C. (2006). E-commerce challenges: The story of on-line groceries. E-Commerce Business - Technology - Society. 3rd Ed., New Jersey: Prentice Hall, 9: 1-4.

Miyazaki, A. D., \& Fernandez, A. (2001). Consumer perceptions of privacy and security risks for online shopping. Journal of Consumer Affairs, 35(1), 27-44.

Ratnasingham, P., \& Kumar, K. (2000). Trading partner trust in electronic commerce participation. In Proceedings of the twenty first international conference on Information systems (pp. 544-552). Association for Information Systems.

Rose, G., Khoo, H., \& Straub, D. W. (1999). Current technological impediments to business-to-consumer electronic commerce. Communications of the AIS, 1(1), 11-17.

Sathye, M. (1999). Adoption of internet banking by Australian consumers: an empirical investigation. International Journal of bank marketing, 17(7), 324-334.

Schneider, G.P. (2004). Electronic Commerce: The Second Wave, 5th ed., Thomson Learning, Wadsworth.

Spiliopoulos, S. (2007), "Non technical limitations of e-commerce", AGROWEB eCommerce Training Material, available at: www2.ellinogermaniki. gr/ep/agroweb/htmls/lessons/ commerce1/113.htm (accessed 20 June, 2007).

Suki, N. M., \& Ramayah, T. (2010). User Acceptance of the E-Government Services in Malaysia: Structural Equation Modelling Approach. Interdisciplinary Journal of Information, Knowledge \& Management, 5 (3), $12-$ 19.

Turban, E., Ephraim M. and James W. (2004). Information Technology for Management: Transforming Organizations in the Digital Economy. New York: Wiley \& Sons.

Vickers, M., (2000). Models from mars. Business Week, 4(3), 58-59.

Wilson, S. and Abel, I. (2002). So you want to get involved in e-commerce. Industrial Marketing Management, 31(5).85-94.

Ystats (2020). Saudi-arabia-b2c-e-commerce-market. Retrieved January, 2020 from https://www.ystats.com/market-reports/saudi-arabia-b2c-e-commerce-market-2019/ 